\title{
Solar lentigoda yoğun atımlı ıșk (Intense Pulse Light) tedavisinin etkinliği: Retrospektif çalıșma
}

Ege Üniversitesi Tıp Fakültesi, Deri ve Zührevi Hastalıklar Anabilim Dalı, İzmir, Türkiye

*İstanbul Bilim Üniversitesi, Deri ve Zührevi Hastalıklar Anabilim Dalı, İstanbul, Türkiye

\section{Özet}

Giriş: Intense Pulsed Light (IPL); epilasyon, hiperpigmentasyon, non-ablatif deri yenileme, yüzeyel vasküler lezyonların tedavisinde kullanılan, dalga boyu 500-1200 nm arasında değişen bir ışık sistemidir. IPL'nin etki mekanizmasının epidermal keratinosit ve melanositlerdeki selektif fototermolize bağlı gerçekleşen fokal epidermal koagülasyon olduğu düşünülmektedir. Solar lentigo tedavisinde çeşitli lazer sistemleri kullanılabilmektedir. Bu çalışmanın amacı solar lentigoda IPL'nin etkinliğini araştırmaktır.

Yöntem ve Araçlar: Kozmetoloji Ünitesi'nin Mart 2007-Kasım 2010 tarihleri arasındaki arşivi solar lentigo tanılı olgular için retrospektif olarak tarandı. Klinik ve dermoskopik olarak solar lentigo tanısı almış ve IPL (L900 A\&M IPL) tedavisi uygulanmış 139 hasta dosyası incelendi. İşlem öncesinde bilgilendirilmiş, onamları alınmıştı. Bunlar arasından tedavi öncesi ve sonrasında fotoğrafları çekilmiş, kontrollerine düzenli gelmiş olan 42 hasta çalışmaya dahil edildi.

Bulgular: Çalışmaya 41 kadın, 1 erkek toplam 42 hastanın 52 lezyonu alındı. Hastaların yaş ortalamaları 42 $\pm 9,6$, yaş aralığı 33-80 idi. Lezyonların 27'si (\%51,9) yanakta, 7'si (\%13,5) zigomatik alanda, 6'sı (\%11,5) çenede, 4'ü $(\% 7,7)$ alında, 4'ü $(\% 7,7)$ el sırtında, 2'si (\%3,8) burunda, 2'si $(\% 3,8)$ kolda yerleşim göstermekteydi. IPL seans sayısı 1-7 seans $($ ort:3,28) arasında değişmekteydi. Tedavi sonrası iyileşme 30 lezyonda (\%57,7) \%75 üzerinde, 9 lezyonda (\%17,3) \%50-75 arası, 9 lezyonda $(\% 17,3) \% 25-50$ arası, 4 lezyonda $(\% 7,7) \% 25$ altındaydı. Sonuç: Çalışmamızın sonuçlarına göre, IPL, solar lentigo tedavisinde etkili, ucuz ve yan etki açısından güvenli bir yöntem olarak kabul edilebilir. (Türkderm 2014; 48: 39-42)

Anahtar Kelimeler: IPL, solar lentigo, tedavi

\section{Summary}

Background and Design: Intense Pulsed Light (IPL) is a light system of 500-1200 nm wavelength which is used for hair removal and nonablative skin resurfacing as well as for the treatment of hyperpigmentation and superficial vascular lesions. The mechanism of action is thought to be the focal epidermal coagulation due to selective photothermolysis in the epidermal keratinocytes and melanocytes. A variety of laser systems can be used in the treatment of solar lentigo. The aim of this study was to investigate the effectiveness of IPL in solar lentigo.

Materials and Methods: We retrospectively reviewed the medical records of patients with the diagnosis of solar lentigo in our Cosmetology Unit from March 2007 to November 2010. There were 139 files of patients who received clinical and dermoscopic diagnosis of solar lentigo and treated by IPL (L900 A\&M). Informed consent was taken from all patients. Among them, 42 patients, who had attended regular follow-up visits and had pictures taken both before and after treatment, were included in the study.

Results: A total of 52 lesions in 42 female and 1 male patients were included in the study. The mean age of the patients was $42 \pm 9.6$ (33-88) years. Thirty-seven lesions (51.9\%) were on the cheek, 7 lesions (13.5\%) were on the zygoma, 6 lesions (11.5\%) were on the chin, 4 lesions

Yazışma Adresi/Address for Correspondence: Dr. Bengü Gerçeker Türk, Ege Üniversitesi Tip Fakültesi, Deri ve Zührevi Hastallklar Anabilim Dall, İzmir, Türkiye Tel.: +90 2323903831 E-posta: bengugerceker@yahoo.com Geliş Tarihi/Received: 30.12.2012 Kabul Tarihi/Accepted: 09.04.2013 


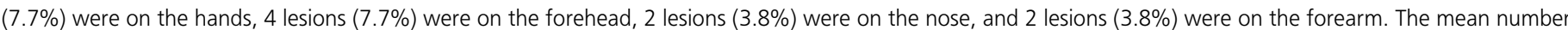

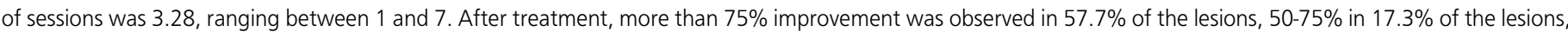
$25-50 \%$ in $17.3 \%$ of the lesions, and less than $25 \%$ improvement was obtained in $7.7 \%$ of the lesions.

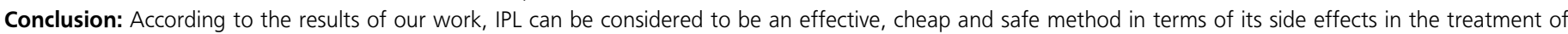
solar lentigo. (Turkderm 2014; 48: 39-42)

Key Words: IPL, solar lentigo, treatment

\section{Giriş}

Solar lentigo fotoyaşlanmanın bir bulgusu olarak güneş gören bölgelerde gelişen hiperpigmente maküllerdir. Solar lentigonun tedavisi oldukça çeşitlidir. Leke giderici topikal kozmetik ürünler, kriyoterapi, kimyasal soyma işlemi, ablatif ve non-ablatif lazerler ile Intense Pulsed Light (IPL) tedavide tek başına ya da kombine halde kullanılabilmektedir ${ }^{1-3}$.

IPL, epilasyon, hiperpigmentasyon, deri yenileme, yüzeyel vasküler lezyonların tedavisinde kullanılan, dalga boyu 500-1200 nm arasında değişen non-ablatif bir ışık sistemidir. Etki mekanizması selektif fototermolizdir. Kullanılan filtreler yardımıyla daha kısa dalga boyları devre dışı bırakılarak ışığın belli bir hedefe yöneltilmesi sağlanır ${ }^{3,4}$. $\mathrm{Bu}$ çalışmada amaç, solar lentigo tanılı olgularda IPL tedavisinin etkinliğini araştırmaktır.

\section{Gereç ve Yöntem}

Kozmetoloji Ünitesi'ne Mart 2007-Kasım 2010 tarihleri arasında solar lentigo tanısı ile başvurmuş, klinik ve dermoskopik olarak solar lentigo tanısı almış ve IPL tedavisi uygulanmış 139 hastanın dosyası retrospektif olarak değerlendirildi. Tedavi öncesi ve sonrasında fotoğrafları çekilmiş, kontrollerine düzenli gelmiş olan 42 hasta çalışmaya alındı. IPL sisteminin (A\&M Technology, L900-France) dalga boyu 620-1000 nm, fluence değerleri 4-14 mj/ $\mathrm{cm}^{2}$ arasında değişmekte, spot boyutu $2 \mathrm{~cm}^{2}$ idi. Hekim tarafından solar lentigonun pigmentasyon derecesinin cihazın üzerindeki panelden (açık, orta, koyu) seçilmesini takiben dozlar, cihaz tarafından otomatik olarak ayarlamakta idi. Tedavi sonrası yanıtlar pigmentasyondaki açılmaya göre \%75 ve üzerinde iyileşme, \%50-75 iyileşme, \%25-50 iyileşme olarak derecelendirildi, \%25 altında renkte açılma ise yanıtsızlık olarak kabul edilmişti. Tedavi sonrasında lezyonlarda gelişen eritem için soğuk uygulama yapıımıştı. Hastalar birkaç gün içinde oluşacak hafif renk koyulaşması ve tedavi konusunda aydınlatıldıktan sonra imzalı onayları alınmıştı. Hastalara güneşten koruyucu kullanımı önerilmiş ve IPL tedavisi öncesi ve sonrası lezyonların fotoğrafı çekilmişti.

\section{Bulgular}

Çalışmaya 41 kadın $(\% 97,6), 1$ erkek $(\% 2,4)$ toplam 42 hasta alındı. Hastaların yaş ortalamaları 42 $\pm 9,6$, yaş aralığı 33-80 idi. Hastaların Fitzpatrick deri tipleri 22 olguda $(\% 52,4)$ Tip II, 20 olguda $(\% 47,6)$ Tip III idi. IPL uygulanan lezyon sayısı 52 idi. Lezyonların 27'si $(\% 51,9)$ yanakta, yedisi $(\% 13,5)$ zigomatik alanda, altısı $(\% 11,5)$ çenede, dördü $(\% 7,7)$ alında, dördü $(\% 7,7)$ el sırtında, ikisi $(\% 3,8)$ burunda, ikisi $(\% 3,8)$ kolda yerleşim göstermekteydi. Seanslar arasındaki süre 4-5 hafta idi. Tedavi sonrası 30 lezyonda $(\% 57,7) \% 75$ üzeri (Resim 1,2,3), 9 lezyonda (\%17,3), \%50-75 arası, 9 lezyonda (\%17,3) \%2550 arası, 4 lezyonda $(\% 7,7) \% 25$ altı renk açılması saptandı. Lezyon yerleşimi ile tedavinin etkinliği arasında istatistiksel bir anlamlılık saptanmadı $(p>0,05)$.

Uygulanan IPL seans sayısı 1 ile 7 seans (ort. 3,28) arasında değişmekteydi. Dokuz lezyona $(\% 17,3) 1$ seans, dokuz lezyona $(\% 17,3) 2$ seans, on üç lezyona $(\% 25) 3$ seans, altı lezyona $(\% 11,5)$ 4 seans, on lezyona $(\% 19,2) 5$ seans, üç lezyona $(\% 5,8) 6$ seans, iki lezyona $(\% 3,8) 7$ seans uygulama yapılmıştı. Lezyonların yerleşimine göre ortalama seans sayısı ise yanak bölgesinde 3,8 seans, zigomatik bölgede 3,0 seans, çene bölgesinde 2,8 seans, alın bölgesinde 2,75, el sırtında 1,25 seans, burun bölgesinde 4,0 seans, kol bölgesinde 2,5 seans idi. Lezyon yerleşimine göre uygulanan seans sayısı arasında istatistiksel bir anlamlılık saptanmadı $(p>0,05)$. Deri tipi II olanlarda ortalama 3,2 seans uygulama ve deri tipi 3 olanlarda ortalama 3,6 seans uygulama yapılmıştı. Deri tipine göre uygulanan seans sayısı ve tedavi etkinliği dağılımı benzer oranlarda saptandı. Tedavi sonrası

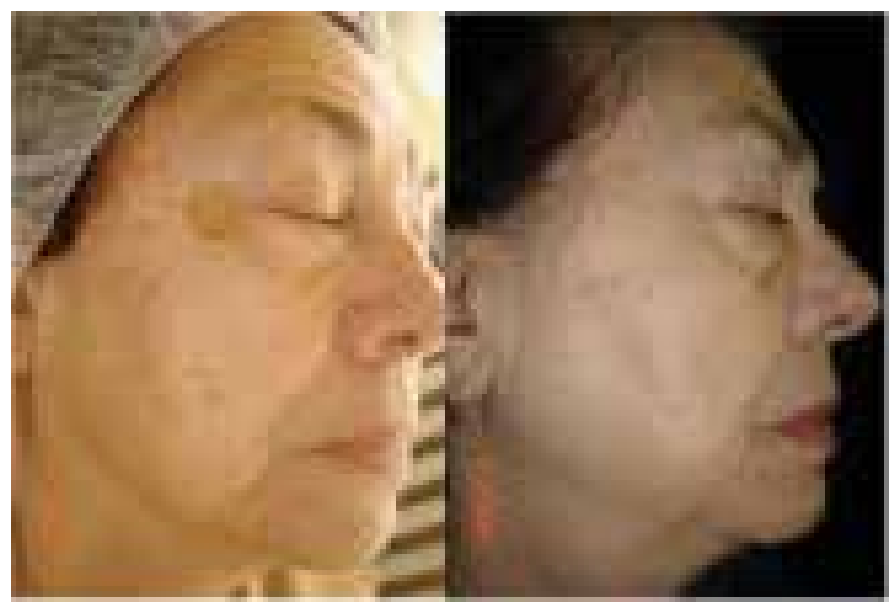

Resim 1. a. Zigomatik bölge ve yanaklardaki solar lentigoların tedavi öncesi, b. tedavi sonrası görünümü

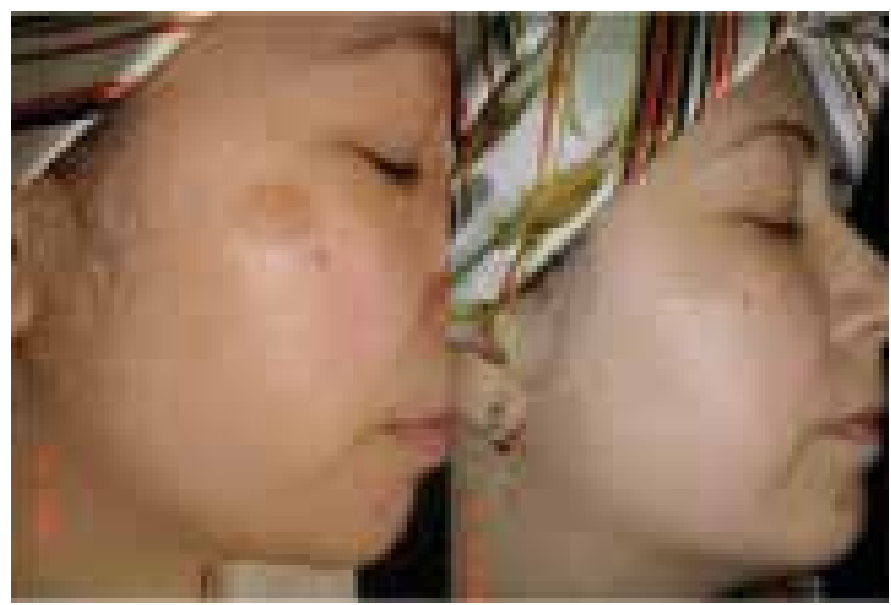

Resim 2. a. Sağ yanaktaki solar lentigonun tedavi öncesi, b. tedavi sonrası görünümü 


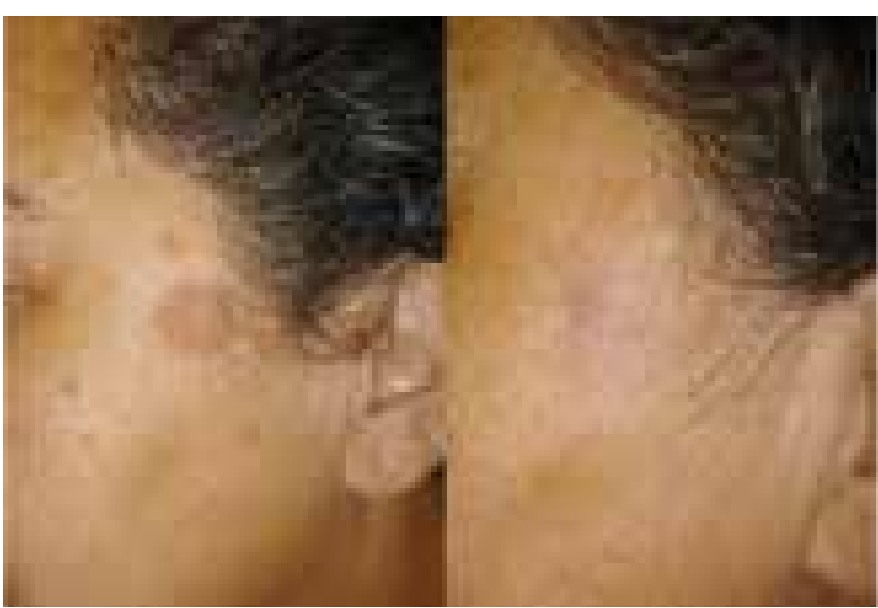

Resim 3. a. Sol yanaktaki solar lentigonun tedavi öncesi, b. tedavi sonrası görünümü

geçici eritem dışında hiçbir yan etki gözlenmedi.

\section{Tartışma}

Çalışmamızda solar lentigolu olguların \%75'inde pigmentasyonda \%50 üzerinde gerileme elde edilmiştir. İlgili literatür gözden geçirildiğinde IPL'nin efelid ve solar lentigo tedavisinde \%5886 'lara varan bir etkinlik gösterdiği görülmüştür ${ }^{5-9}$. El lokalizasyonlu solar lentigoda olguların $\% 62$ 'sinde $\% 50$ ve üzerinde iyileşme bildirilmektedir ${ }^{7}$. Bizim çalışmamızda da literatür ile benzer bir etkinlik elde edilmiştir. IPL'nin genellikle 3-5 seans sonrasında solar lentigo tedavisinde başarılı olduğu görülmektedir6,9,10. Bizim çalışmada da ortalama tedavi seans sayısı yaklaşık 3 olarak bulunmuştur. Efelid tedavisinde ise gereken ortalama seans sayısı solar lentigo olgularına göre belirgin olarak daha düşük $(1,47)$ bildirilmiştir ${ }^{5}$.

Çalışmamızda lezyon yerleşimi ile tedavi etkinliği ya da seans sayısı arasında anlamlı bir ilişki saptanmamıştır. Çalışmamızda istatistiksel olarak anlamlı bulunmasa da el yerleşimli lentigolarda diğer yerleşimlere göre ortalama seans sayısının 1,25 olduğu dikkati çekmektedir. Literatürde lokalizasyona ve deri tipine göre etkinlik oranları ya da seans sayısı karşılaştırması ile ilgili veriye ulaşılamamıştır. Konisha ve ark.'ı 18 olguluk serilerinde IPL tedavisinin solar lentigolu olgularda \%28 belirgin iyileşme, \%39 hafif iyileşme sağladığını \%33 oranında ise etkisiz olduğunu bildirmişlerdir ${ }^{9}$. Solar lentigolu olgularda IPL tedavisine yanıtın objektif yöntemlerle ölçüldüğü çalışmalardan spektrofotometrik yöntemle yapılan değerlendirmede \%66 gerileme saptanmıştır ${ }^{10}$. Peutz-Jeghers sendromu ve nörofibromatozis gibi maküler pigmentasyonların görüldüğü hastalıklarda da IPL tedavisinin kozmetik iyileşme sağladığı belirtilmektedir ${ }^{11}$. IPL uygulamalarının postinflamatuvar hiperpigmentasyonda da etkili olduğu bildirilmiştir. Toksik epidermal nekrolizis sonrası hiperpigmentasyon gelişen iki hastada IPL tedavisi dört hafta aralarla beş seans şeklinde uygulanmış ve \%80 oranında deri renginde açılma Mexameter ile kantitatif olarak ölçülmüş, histopatolojik olarak da pigmentasyonun azaldığı gösterilmiştir ${ }^{12}$.

Videomikroskopik ve histopatolojik olarak yapılan değerlendirmeler sonucunda da tedavi sırasında IPL'nin enerjisini selektif olarak epidermal keratinosit ve melanositlerdeki melanine aktardığı ve burada yol açtığı selektif fototermolize bağlı olarak bu alanlarda fokal epidermal koagülasyon olduğu düşünülmektedir. Bu süreci mikro kurut gelişimi izlemekte, bu kurutların kalkmasıyla da iyileşmenin elde edildiği gözlenmektedir. Histopatolojik incelemelerde bazal tabakalarda melaninin tedavi ile azaldığı gösterilmiş, tedaviye bağlı skar formasyonu ya da kollajen hasarı izlenmemiştir ${ }^{13}$. Konfokal mikroskopi ile yapılan objektif değerlendirme sonucunda ise epidermal bazal tabakadaki melanozomların IPL sonrası ortadan kalktığı belirtilmektedir ${ }^{14}$

Solar lentigo tedavisinde, IPL'nin yanı sıra çeşitli lazer sistemleri de değişik başarı oranları ile uygulanabilmektedir',2,15,16. Asyalılarda solar lentigo tedavisinde Q-anahtarlı lazerlerin etkinlik açısından IPL'ye üstün olduğu gösterilmiştir. Ancak postinflamatuvar hiperpigmentasyon, hipopigmentasyon ve skar gelişimi riski taşıdığı, uygulama sonrası hastanın günlük hayatına dönmesinin zaman alabildiği belirtilmektedir. IPL'nin Asyalılarda postinflamatuvar hiperpigmentasyona yol açmaması açısından daha güvenilir olduğu, uygulama sonrası hastanın günlük yaşantısına dönebilmesinin de bir diğer avantajı olduğu vurgulanmaktadır ${ }^{16}$. Bu nedenle özellikle deri tipi III ve IV olan olgularda solar lentigo tedavisinde Q-anahtarlı Alexandrite yerine IPL uygulanması önerilmektedir ${ }^{16}$.

Yoğun atımlı ışık tedavisi sırasında pigmente lezyonlar için daha düşük dalga boyu (550 nm gibi) kullanılmaktadır ${ }^{1}$. Vuruş süresinin ise melanozomların termal relaksasyon zamanından yani 70-250 ms'den kısa olması gerektiği belirtilmektedir. Uygulamaya bağlı yan etkileri azaltmak için dalga boyu deri tipine göre belirlenmelidir ${ }^{1,2}$. IPL tedavisinin yan etkileri tedavinin yoğunluğuna bağlı olarak pigmentasyon değişiklikleri, skar formasyonu, vezikül ve uzamış eritem gelişimi olarak belirtilmektedir. Ancak literatürde efelid ve solar lentigoda IPL uygulamalarını konu alan çalışmalarda, yüzeyel erozyon dışında yan etki gelişimi bildirilmemiştiı ${ }^{5-7,9-14,16}$. Bizim serimizde de olguların tamamı günlük yaşantısına aynı gün dönebilmiştir. Kontrollerde hastalarda uygulamaya bağlı herhangi bir yan etki gözlenmemiştir.

Sonuç olarak, çoğu kez kozmetik sorun olarak karşımıza çıkan solar lentigonun tedavisinde seçilmiş olgularda IPL, etkili, ucuz ve güvenli bir yöntem olarak kabul edilebilir.

\section{Kaynaklar}

1. Lipper GM, Anderson RR: Lasers in Dermatology. Fitzpatrick's Dermatology of General Medicine. Ed. Freedberg IM, Eisen AZ, Wolff KK. 6'ıncı Baskı. Newyork, McGraw-Hill, 2003;2493-2515.

2. Ortonne JP, Pandya AG, Lui H, Hexsel D: Treatment of solar lentigines. J Am Acad Dermatol $2006 ; 54: 262-71$.

3. Bahmer F, Drosner $\mathrm{M}$, Hohenleutner $\mathrm{U}$, et al: Recommendation for laser and intense pulsed light (IPL) therapy in dermatology. J Dtsch Dermatol Ges 2007;5:1036-42.

4. Ertam I, Karaca N, Ünal I, Alper S: Fasiyal Telenjiektazide IPL (Yoğun Atıml Işı-Intense Pulse Light): Ege Üniversitesi Tıp Fakültesi Dermatoloji Anabilim Dalı Tedavi Sonuçları. Türk Dermatoloji Dergisi 2008: 2: 73-6.

5. Huang $Y L$, Liao $Y$, Lee $S H$, Hong HS: Intense pulse light in the treatment of facial freckles in Asian skin. Dermatol Surg 2002;28:1007-12.

6. Kawada A, Shiraishi H, Asai M, et al: Clinical improvement of solar lentigines and ephelides with an intense pulsed light source. Dermatol Surg $2002 ; 28: 504-8$.

7. Sasaya H, Kawada A, Wada T, Hirao A, Oiso N: Clinical effectiveness of intense pulsed light therapy for solar lentigines of the hands. Dermatol Ther 2011;24:584-6.

8. Campolmi P, Bonan P, Cannarozzo G, et al: Intense pulsed light in the treatment of non-aesthetic facial and neck vascular lesions: report of 85 cases. J Eur Acad Dermatol Venereol 2011;25:68-73. 
9. Konishi N, Kawada A, Kawara S, et al: Clinical effectiveness of a novel intense pulsed light source on facial pigmentary lesions. Arch Dermatol Res 2008;300: 65-7.

10. Kawana S, Ochiai H, Tachihara R: Objective evaluation of the effect of intense pulsed light on rosacea and solar lentigines by spectrophotometric analysis of skin color. Dermatol Surg 2007;33:449-54.

11. Remington BK, Remington TK. Treatment of facial lentigines in PeutzJeghers syndrome with an intense pulsed light source. Dermatol Surg 2002;28:1079-81.

12. Paquet P, Pierard GE: Intense Pulsed Light Treatment of Persistent Facial Hypermelanosis Following Drug-Induced Toxic Epidermal Necrolysis Dermatol Surg 2004;30:1522-25
13. Kawada A, Asai M, Kameyama $H$, et al: Videomicroscopic and histopathological investigation of intense pulsed light therapy for solar lentigines. J Dermatol Sci 2002;29:91-6.

14. Yamashita T, Negishi K, Hariya $T$, et al: Intense pulsed light therapy for superficial pigmented lesions evaluated by reflectance-mode confocal microscopy and optical coherence tomography. J Invest Dermatol 2006;126:2281-6.

15. Chan $\mathrm{HH}$ : The use of lasers and intense pulsed light sources for the treatment of acquired pigmentary lesions in Asians. J Cosmet Laser Ther 2003:5:198-200.

16. Wang CC, Sue YM, Yang CH, Chen CK: A comparison of Q-switched alexandrite laser and intense pulsed light for the treatment of freckles and lentigines in Asian persons: a randomized, physician-blinded, split-face comparative trial. J Am Acad Dermatol 2006;54:804-10. 